Edgar Chedrawy BSc,

Richard Hall MD FRCPC FCCP, Vivian Nedelcu RN

\section{Postoperative elevation of creatine kinase (CK-MB): does it contribute to diagnosis of myocardial infarction?}

Purpose: This retrospective study sought to determine the benefit of measurement of changes in plasma creatine kinase - myocardial band (CK-MB) levels in elective postoperative high risk surgical patients beyond that obtained from the surface 12 lead ECG.

Methods: The charts of 111 patients admitted to the surgical intensive care unit (SICU) of a tertiary level university teaching hospital were reviewed. They were screened using predetermined definitions of myocardial infarction (MI) (as reflected by changes in the 12 lead surface ECG (Minnesota code) or elevations in CK-MB) for complications such as pulmonary oedema, congestive heart failure, arrhythmias, or cardiogenic shock. Four groups were identified based on changes in the ECG indicative of MI (Present - ECG + or Absent - ECG-) and elevations of CK-MB (Present - CKMB + or Absent - CKMB-) and compared for the incidence of complications.

Results: No patient with ECG- findings had a complication. Fifteen patients with ECG + findings were identified and all had complications. Fourteen of these patients had CKMB + results. In contrast, 29 patients with CKMB+ results alone (i.e., ECG-) had no complications.

Conclusion: Clinically important (i.e., requiring therapeutic intervention) postoperative myocardial infarction was detected by ECG changes. The benefit of determining changes in CK-MB was minimal from a therapeutic perspective.

Objectif : Cette étude rétrospective visait à comparer les avantages, à la période postopératoire, de la mesure des variations de la créatine phosphokynase-MB (CK-MB) à ceux de l'ÉCG à 12 dérivations chez des patients à haut risque.

Méthodes : Révision des dossiers de III patients admis à l'unité des soins intensifs chirurgicaux d'un hôpital universitaire de soins tertiaires. Tout en utilisant les définitions prétablies de l'infarctus du myocarde (IM) (changements à l'ÉCG à 12 dérivations (code du Minnesota) ou augmentation de la CK-MB), on a recherché les complications comme l'oedème pulmonaire. l'insuffisance cardiaque congestive, les arythmies ou le choc cardiogénique. Quatre groupes ont été identifiés sur la base des changements ÉCG indicatifs de I'IM (IM présent avec ECG + ou absent avec ÉCG-) et des élévations de la CK-MB (IM présent avec CPK-MB + ou absent avec CPK-MB-) et comparés en rapport avec l'incidence des complications.

Résultats : Aucun des patients avec des signes négatifs à l'ÉCG n'a souffert de complications. Quinze patients avec des signes positifs à l'ÉCG ont été reconnus et ils ont tous souffert de complications. Quatorze de ces patients avaient des dosages de CPK-MB élevés. Par contre, 29 patients avec des CPK-MB + seulement (c.-à.-d. ÉCG négatif) n'ont pas souffert de complications.

Conclusion : Les changements à l'ECG ont détecté l'infarctus du myocarde postopératoire clinique (c-a-d. nécessitant un traitement). Dans la perspective thérapeutique, la mesure des changements de CPK-MB offre peu d'avantages.

From the Departments of Anaesthesia, Pharmacology and Surgery, Queen Elizabeth II Health Sciences Centre and Dalhousie University, The New Halifax Infirmary, 1796 Summer Street, Halifax, Nova Scotia, Canada B3H 3A7.

Address correspondence to: Dr. Richard I. Hall.

Accepted for publication May 3, 1997. 


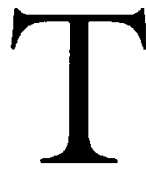

HE diagnosis of Acute Myocardial Infarction has traditionally been based on World Health Organization (WHO) criteria which require two of three positive findings from the following: 1) a clinical history of prolonged ischaemic chest pain; 2) a characteristic sequence of ECG changes; or 3) increased plasma concentrations of cardiac enzymes (creatine kinase-myocardial band isozyme (CK-MB) or lactate dehydrogenase (LDH). ${ }^{1}$

In the perioperative period there are severe limitations to the first two WHO criteria (positive symptoms are often absent or cannot be obtained ${ }^{2-4}$ and ECG changes are often uninterpretable ${ }^{5}$ ) in diagnosing myocardial infarction. The specificity of cardiac enzyme concentration changes in postoperative patients is limited because skeletal muscle injury induced by surgery may nonspecifically increase the postoperative concentration of cardiac enzymes, such as $\mathrm{CK} \cdot \mathrm{MB}{ }^{6-11}$ The sensitivity of $\mathrm{CK}-\mathrm{MB}$ is known to be time-dependent: CK-MB levels start to rise four to eight hours after the onset of infarction, peak at 12-24 $\mathrm{hr}$ and decrease to normal levels within $72 \mathrm{hr}$; therefore, peak values may be missed if sampling times are inappropriate. ${ }^{12}$ Hence, the detection of postoperative myocardial infarction represents an important but challenging diagnostic task. The purpose of this investigation was to determine the additional benefit provided by serial CK-MB measurements for the detection of clinically important (i.e., requiring therapeutic intervention) myocardial infarction in elective, postoperative, surgical patients who had an interpretable electrocardiogram (absence of bundle branch block, paced rhythm, drug effect e.g., digitalis). We hypothesized that, while transient elevations in CKMB concentrations were common, the incidence of clinically important myocardial infarction was much rarer and would be detected by examination of the ECG, with or without measurement of the CK-MB level.

\section{Materials and methods}

Following institutional approval by the Queen Elizabeth II Health Sciences Centre, Victoria General Hospital Site Hospital Research Review Committee, the charts from 111 consecutive postoperative patients admitted over a 12 -month period, who had had CKMB determinations performed while in the SICU, were identified utilising an ICU database. All patients had a preoperative interpretable ECG (i.e., absence of bundle branch block, paced rhythm, or drug effect e.g., digitalis) and were admitted for the first time to the Surgical Intensive Care Unit (SICU) for observation because of a history of ischaemic cardiac disease, and/or because they were undergoing major elective surgery of a nature which would put them at risk for postoperative myocardial ischaemia and infarction (e.g., major vascular surgery). In all such cases, serial ECG's every day for three days, and CK-MB determinations every six hours for $24 \mathrm{hr}$, then at $36 \mathrm{hr}$ and 48 $\mathrm{hr}$, were routinely performed from the time of admission to the ICU. The CK-MB serum levels were determined using an Abbott $I_{M X}{ }^{R}$ chemofluorescence assay.

\section{Study design}

The 111 charts were reviewed for evidence of postoperative myocardial infarction and CK-MB elevation. The standard 12-lead ECG was considered diagnostic of postoperative myocardial infarction (ECG+) when there was the development of either new Q-waves (as defined by the Minnesota Code: 1-1-1 to 1-2-7), ${ }^{13}$ or persistent ST segment changes (Minnesota Code: $4-1$ or $4-2,5-1$ or $5-2){ }^{13}$ The CK-MB increase was considered positive $(\mathrm{CKMB}+)$ when total $\mathrm{CK}$ elevation was twice baseline, with the ratio of CK-MB to total $\mathrm{CK}>5 \%$ of total CK, as determined from serial samples at six hour intervals for $24 \mathrm{hr}$ from the time of admission; or CK-MB concentration $>15$ IU in a single sample. ${ }^{12,14-16}$

The charts were analysed for complications of myocardial infarction (i.e., pulmonary oedema, congestive heart failure, arrhythmias, cardiogenic shock) and the treatment of such complications. Pulmonary oedema diagnosis was based on: 1) clinical signs (shortness of breath, râles); 2) chest radiographic evidence (vascular redistribution, interstitial oedema, alveolar oedema); and 3) requirement for diuretic use (furosemide). Diagnosis of congestive heart failure required: 1) clinical symptoms and signs of pulmonary oedema; 2) signs of new right or left ventricular failure (i.e., central venous pressure (CVP) $>12 \mathrm{mmHg}$, or pulmonary artery occlusion pressure (PAOP) $>18$ $\mathrm{mmHg}$, cardiomegaly, S3, elevated JVP, peripheral oedema); and 3 ) a change in treatment requiring the use of diuretics. Arrhythmias consisted of ventricular tachycardias (defined as $z$ five consecutive beats of a wide complex morphology at a rate $\geq 100$ beats $\mathrm{min}^{-1}$ ), or bradycardias (defined as $\geq 5$ consecutive beats at a rate of $<60$ beats. $\mathrm{min}^{-1}$ regardless of the morphology). Cardiogenic shock was defined as hypotension (systolic BP $<90 \mathrm{mmHg}$ ), with evidence of peripheral and venous congestion (CVP $>12 \mathrm{mmHg}$, PAOP $>18$ $\mathrm{mmHg}$ ) and requiring inotropic support. Management interventions required to treat these complications were recorded. These definitions were defined prior to the chart review. 


\section{Data analysis}

Based on the ECG as the "gold standard," routine definitions of sensitivity, specificity and predictive values were used: ${ }^{17}$ Sensitivity $=\mathrm{TP} /(\mathrm{TP}+\mathrm{FN})$ where $\mathrm{TP}=$ true positives and FN $=$ false negatives; Specificity $=\mathrm{TN} /(\mathrm{FP}+\mathrm{TN})$ where $\mathrm{TN}=$ true negatives and $\mathrm{FP}=$ false positives; Positive Predictive Value $(\mathrm{PPV})=\mathrm{TP} /(\mathrm{TP}+\mathrm{FP}) ;$ Negative Predictive Value $(\mathrm{NPV})=\mathrm{TN} /(\mathrm{TN}+\mathrm{FN})$. Chi-Square analysis was applied to categorical data. One-way ANOVA was used to test the difference between the mean values for continuous data. $P<0.05$ was considered statistically significant.

\section{Results}

\section{Demographic and clinical data}

Analysis of the data identified four groups based on whether the ECG was positive (ECG+) or negative (ECG-) and the CK-MB was positive (CKMB+) or negative (CKMB-) for the development of myocardial infarction as defined. The study groups [ECG+, $\mathrm{CKMB}+]$, [ECG-, CKMB+] and [ECG-, CKMB-] were compared with respect to age, sex, previous history of ischaemic heart disease, length of stay in SICU and death (Table I). [ECG+, CKMB+] patients were older, more likely to have a history of ischaemic heart disease and stayed in the ICU longer than [ECG-, CKMB+] patients. The site of the surgical procedure is given in Table II. The highest absolute value of CK-MB for any patient did not differ between patients with ECG+ (47 \pm 40 units) ps ECG- $(24 \pm 68)$ results.

\section{Electrocardiographic and $C K-M B$ findings}

Fifteen patients had ECG changes consistent with myocardial infarction (ECG+, Table III); the prevalence of postoperative MI in the SICU population studied was, therefore, $13.5 \%$. Fourteen patients with (ECG+) results also had $\mathrm{CK}-\mathrm{MB}$ elevations [ECG+, $\mathrm{CKMB}+]$. The one patient with [ECG+, $\mathrm{CKMB}$-] findings experienced a postoperative course complicated by pulmonary oedema requiring treatment with diuretics. Of the 96 remaining patients with no ECG changes (ECG-), 67 had no CK-MB elevation [ECG-, CKMB-]. Twentynine patients had [ECG-, CKMB+] findings (Table III).

\section{Complications and management changes}

Compared with patients with [ECG-, CKMB+] results, patients with $[\mathrm{ECG}+, \mathrm{CKMB}+]$ suffered more morbidity (Table IV) in the form of pulmonary oedema $(92 \%$ vs $0 \%, P<0.05)$, congestive heart failure $(85.7 \%$ vs $0 \%, P<0.05)$ and arrhythmias $(42.8 \%$ vs $0 \%$,

TABLE I Demographic and clinical characteristics of [ECG+, CKMB+], [ECG-, CKMB+] and [ECG-, CKMB-] study subjects

\begin{tabular}{llll}
\hline Characteristic & $\begin{array}{l}{[E C G+, C K M B+]} \\
n=14\end{array}$ & $\begin{array}{l}{[E C G ;, C K M B+]} \\
n=29\end{array}$ & $\begin{array}{l}{[E C G ;, C K M B-]} \\
n=67\end{array}$ \\
\hline Age (yr) & $73.5 \pm 7.2$ & $62.7 \pm 15.4$ & $63.9 \pm 16.7$ \\
Sex $(M / F)$ & $9 / 5$ & $13 / 16$ & $46 / 21$ \\
IHD & 12 & $13 *$ & $28^{\star}$ \\
SICU Stay (days) & $10.4 \pm 8.4$ & $5.7 \pm 6.9$ & $6.7 \pm 11.5$ \\
Death (Total) & 5 & 7 & 14 \\
Cause of Death: & 4 & 3 & 1 \\
cardiac arrest & 4 & 2 & 3 \\
respiratory failure & & 2 & 10 \\
multi-organ failure & 1 & & \\
\hline
\end{tabular}

$\star P<0.05$ vs $[\mathrm{ECG}+, \mathrm{CKMB}+]$

IHD = previous history of ischaemic heart disease; SICU Stay = number of days spent in SICU;

Death $=$ death during intensive carc unit stay.

N.B. One patient with [ECG+,CKMB-] results is not included in the Table.

TABLE II Site of surgical procedure

\begin{tabular}{llll}
\hline Surgery (Total) & $\begin{array}{l}{[E C G+, C K M B+]} \\
n=14\end{array}$ & $\begin{array}{l}{[E C G-, C K M B+]} \\
n=29\end{array}$ & $\begin{array}{l}{[E C G-, C K M B-]} \\
n=67\end{array}$ \\
\hline Gastrointestinal (23) & 5 & 9 & 9 \\
Hepatobiliary/Pancreatic(19) & & 3 & 16 \\
Peripheral Vascular (22) & 6 & 5 & 11 \\
Thoracic (15) & 3 & 3 & 9 \\
Orthopaedic/Trauma (16) & & 6 & 10 \\
Urological (4) & 3 & 4 \\
Other (11) & & 3 & 8 \\
\hline
\end{tabular}

N.B. One patient with [ECG,$+ \mathrm{CKMB}-]$ underwent peripheral vascular surgery. 
TABLE III Association of serial CK-MB measurements with ECG changes

\begin{tabular}{llll}
\hline CK-MB & ECG + & ECG- & Total \\
CKMB + & $14(T P)$ & $29(\mathrm{FP})$ & $43(\mathrm{TP}+\mathrm{FP})$ \\
CKMB & $1(\mathrm{FN})^{*}$ & $67(\mathrm{TN})$ & $68(\mathrm{FN}+\mathrm{TN})$ \\
Total & $15(\mathrm{TP}+\mathrm{FN})$ & $96(\mathrm{FP}+\mathrm{TN})$ & $111(\mathrm{TP}+\mathrm{FP}+\mathrm{TN}+\mathrm{FN})$ \\
Sensitivity & $\mathrm{TP} /(\mathrm{TP}+\mathrm{FN})=$ & $14 / 15=$ & $93.3 \%$ \\
Specificity $=$ & $\mathrm{TN} /(\mathrm{FP}+\mathrm{TN})=$ & $67 / 96=$ & $69.7 \%$ \\
PPV $=$ & $\mathrm{TP} /(\mathrm{TP}+\mathrm{FP})=$ & $14 / 43=$ & $32.5 \%$ \\
NPV $=$ & TN/(TN $+\mathrm{FN})=$ & $67 / 68=$ & $98.5 \%$ \\
\hline
\end{tabular}

*This patient's postoperative course was complicated by pulmonary oedema.

TP = True Positive; TN = True Negative; FP = False Positive; FN = False Negative PPV = Positive Predictive Value; $\mathrm{NPV}=$ Negative Predictive Value

TABLE IV Comparison of complications and changes in management of [ECG+, CKMB+], [ECG-, CKMB+] and [ECG-, CKMB-] study subjects

\begin{tabular}{llll}
\hline Complication & {$[E C G+, C K M B+]$} & $\begin{array}{l}{[E C G-, C K M B+]} \\
n=29\end{array}$ & $\begin{array}{l}{[E C G, C K M B-]} \\
n=67\end{array}$ \\
\hline Pulmonary Oedema & 13 & $0^{*}$ & $0^{*}$ \\
CHF & 12 & $0^{*}$ & $0^{*}$ \\
Arrythmias & 6 & $0^{*}$ & $0^{*}$ \\
Cardiogenic Shock & 1 & 0 & 0 \\
$\mathrm{O}_{2}$ Therapy & 13 & $15^{*}$ & $46^{*}$ \\
Intubated & 14 & $8^{*}$ & $37^{\star}$ \\
\hline
\end{tabular}

${ }^{*} P<0.05$ vs $[\mathrm{ECG}+, \mathrm{CKMB}+]$

$\mathrm{CHF}=$ Congestive Heart Failure; $\mathrm{PE}=$ Pulmonary Embolism; $\mathrm{O}_{2}$ Therapy $=$ oxygen therapy initiated in the postoperative course;

Intubated $=$ therapy initiated in the postoperative course

$P<0.05)$. They required more interventions such as oxygen therapy $(92.8 \%$ vs $51.7 \%, P<0.05)$ and tracheal intubation for new onset respiratory failure ( $100 \%$ vs $27.5 \%, P<0.05$ ) as a result of their postoperative myocardial infarctions.

\section{Discussion}

The relationship between perioperative myocardial ischaemia and adverse cardiac outcomes such as congestive heart failure and ventricular arrhythmias has been well documented. ${ }^{2-4,18}$ Postoperative myocardial infarction has been associated with higher in-hospital mortality rates ${ }^{2,18}$ and a higher incidence of long-term adverse cardiac outcomes. ${ }^{2-4}$ This retrospective investigation explored the additional role that $\mathrm{CK}-\mathrm{MB}$ determination might play, beyond that of an interpretable ECG, in detecting and managing elective postoperative patients at increased risk for cardiac complications. We have determined that, in patients with an interpretable ECG, measurement of CK-MB added little diagnostic information regarding the likelihood for development of complications, beyond that provided by changes in the ECG.

Patients with [ECG+, CKMB+] were older and more likely to have a previous history of ischaemic heart disease than patients with [ECG-, CKMB+] results (Table I). Patients with [ECG+, CKMB+] results also suffered more morbidity and required more interventions (Table III) as a result of their postoperative myocardial infarctions, when compared with patients with elevations in CK-MB alone. Hence, clinically important, postoperative, myocardial infarction was detected by ECG changes, regardless of the CK$M B$ findings.

Of the 111 patient charts reviewed (Table II), 15 patients had ECG changes consistent with myocardial infarction (ECG+), 14 of whom had CK-MB elevations [ECG+, CKMB+] - i.e., true positives by our definition of myocardial infarction. The sensitivity of CK-MB determinations (vs ECG) in detecting postoperative MI was $93.3 \%$ and the specificity was $69.7 \%$. The low specificity obtained in this study reflects the previously reported high levels of CK-MB occasionally found in postoperative surgical patients with no ischemic chest pain, no ECG changes and no evidence of later cardiac complications. ${ }^{6-11}$

Our sensitivity and specificity results differ considerably from those obtained from determination of serial CK-MB measurements in Emergency Departments ${ }^{19}$ and Coronary Care Units, ${ }^{20}$ where CK-MB is the most sensitive measure of myocardial infarction and a positive result alone carries with it a poor long term progno- 
sis. ${ }^{21-25}$ The practice of measuring CK-MB enzymes in high' risk elective postoperative surgical patients with interpretable ECGs appears to have evolved from coronary care guidelines for investigation of symptomatic chest pain with non-diagnostic ECGs; and a desire not to miss a clinically relevant event (myocardial infarction) in a population of patients at risk for the event, and for whom considerable morbidity occurs if a myocardial infarction is manifest. ${ }^{2-4,18}$ Elective high risk postoperative surgical patients may represent a different population from those presenting to coronary care units. There is frequently absence of chest pain suggestive of ischaemic injury and there is release of CK-MB and other enzymes from noncardiac tissue. ${ }^{7,8,10,11,26}$ Studies of outcomes following elective surgery have based their findings on changes in the ECG at the time of surgery ${ }^{2-4,18,27}$ and the impact of a positive CK-MB alone has not been adequately studied. The results of the present study suggest that, in the absence of ECG changes, the additional information provided did little to improve the diagnosis or therapy. The prognostic value of a positive $\mathrm{CK}-\mathrm{MB}$ result alone for long-term outcome requires further study. Our results confirm and extend the observations of Charlson $e t a l,{ }^{6}$ and others, ${ }^{8-11}$ who also found the value of a positive CK-MB result in a postoperative population to be of little clinical importance. The retrospective nature of our study and the lack of details regarding the severity of illness in the study populations examined in the other studies precludes us from making comparisons on the likelihood of a positive result based on disease severity or magnitude of surgical procedure.

\section{Study limitations}

Our results are predicated on the definitions employed for myocardial infarction and its complications. However, our definitions were developed before the chart review was undertaken and applied evenly to all groups. Our definitions of myocardial infarction follow commonly accepted guidelines while our definitions for complications are, if anything, liberal in nature and not mutually exclusive (e.g., pulmonary oedema may have occurred in patients subsequently diagnosed as having congestive heart failure or cardiogenic shock.) Thus, we may have overestimated the complication rate with bias toward an exaggerated difference between groups. Furthermore, in a retrospective analysis, the timing of events i.e., myocardial infarction then complications $v s$ complications then myocardial infarction may be difficult to ascertain. The differences among groups is striking and we believe it is difficult to explain the magnitude of the results by these confounding factors alone. Our study, due to its retrospective and observational nature, is limited by these confounding variables and bias. The outcomes of false positive [ECG-, CKMB+] and true positive $[\mathrm{ECG}+, \mathrm{CKMB}+]$ groups may have differed for reasons other than myocardial infarction, as no control group was established and, hence, confounding variables cannot be ruled out. Also, bias in chart reviewing and patient assessment may play a role in observational studies. Our results apply only to elective postoperative surgical patients with interpretable preoperative ECGs. The value of routine CK-MB determinations for the detection of perioperative MI in patients with uninterpretable ECGs requires additional study.

\section{Conclusions}

In this retrospective study, clinically significant, postoperative myocardial infarction was detected by ECG changes. The additional diagnostic and prognostic value of CK-MB determination was minimal. No patient with [ECG-, CKMB+] results had a major complication. The benefit ratio for the measurement of CK-MB routinely in elective, postoperative, highrisk surgical patients with interpretable preoperative ECGs may not justify its use in this patient population. A prospective study is required to examine the justification and cost-benefit ratio for measurement of CK$\mathrm{MB}$ in this population including long term follow-up of patients for development of further complications.

\section{References}

1 Roberts $R$. The two out of three criteria for the diagnosis of infarction. Is it passe? (Editorial) Chest 1984; 86: 511-3.

2 Mangano DT, Browner WS, Hollenberg M, et al. Association of perioperative myocardial ischemia with cardiac morbidity and mortality in men undergoing noncardiac surgery. N Engl J Med 1990; 323: 1781-8.

3 Raby KE, Barry J, Creager MA, Cook EF, Weisberg MC, . Goldman $L$. Detection and significance of intraoperative and postoperative myocardial ischemia in peripheral vascular surgery. JAMA 1992; 268: 222-7.

4 Mangano DT, Browner WS, Hollenberg M, Li J, Tateo IM. Study of Perioperative Ischemia Research Group. Long-term cardiac prognosis following noncardiac surgery. JAMA 1992; 268: 233-9.

5 Mangano DT. Preoperative assessment of the patient with ischemic heart disease. In: Mangano DT (Ed.). Preoperative Cardiac Assessment. Philadelphia: J B Lippincott Company, 1990: 1-55.

6 Charlson ME, MacKenzie CR, Ales KL, Gold JP, Fairclough GF Jr, Shires GT. The post-operative electrocardiogram and creatine kinase: implications for diag- 
nosis of myocardial infarction after non-cardiac surgery. $\mathrm{J}$ Clin Epidemiol 1989; 42: 25-34.

7 Adams JE III, Sicard GA, Allen BT, et al. Diagnosis of perioperative myocardial infarction with measurement of cardiac troponin I. N Engl J Med 1994; 330: 670-4.

8 Tsung SH. Circulating CK-MB and CK-BB isoenzymes after gastrointestinal surgery. J Clin Pathol 1982; 35: 200-3.

9 Wukich DK, Callaghan J, Graeber GM, Martyak T, Savory CG, Lyon JJ. Cardiac isoenzyme values after total joint arthroplasty. Clin Orthop 1989; 242: 232-40.

10 Healey JH, Kagen LJ, Velis KP, Levine DB. Creatine kinase $\mathrm{MB}$ in skeletal muscle and serum of spine-fusion patients. Clin Orthop 1985; 195: 282-8.

11 Andersen PT, Nielsen LK, Møller-Petersen J, Egeblad K. Non-cardiac creatine kinase-B activity in serum after abdominal aortic bypass surgery. Acta Chir Scand 1988; 154: 359-62.

12 Irvin $R G$, Cobb FR, Roe CR. Acute myocardial infarction and $\mathrm{MB}$ creatine phosphokinase. Arch Intern Med 1980; 140: 329-34.

13 Blackburn $H$, Keys $A$, Simonson E, Rautaharju $P$, Punsar $S$. The electrocardiogram in population studies. A classification system. Circulation 1960; 21: 1160-75.

14 Raberts $R$. Enzymatic diagnosis of acute myocardial infarction. Chest 1988; 93 (Suppl): 3S-6.

15 Wagner GS. Optimal use of serum enzyme levels in the diagnosis of acute myocardial infarction. The perspective in 1980. Arch Intern Med 1980; 140: 317-9.

16 Roberts $R$, Sobel BE. Creatine kinase isoenzymes in the assessment of heart disease. Am Heart J 1978; 95: 521-8.

17 Riegelman RK, Hirsch RP. Diagnostic discrimination of tests. In: Rielgelman RK, Hirsch RP (Eds.).

Studying a Study and Testing a Test, 2 nd ed. Toronto: Little, Brown and Company, 1989: 151-63.

18 Mangano DT, Wong MG, London MJ, Tubau JF, Rapp $J A$. The Study of Perioperative Ischemia Research Group. Perioperative myocardial ischemia in patients undergoing noncardiac surgery - II: Incidence and severity during the Ist week after surgery. J Am Coll Cardiol 1991; 17: 851-7.

19 Gibler WB, Young GP, Hedges JR, et al. Acute myocardial infarction in chest pain patients with nondiagnostic ECGs: serial CK-MB sampling in the emergency department. Ann Emerg Med 1992; 21: 504-12.

20 Grande P, Cbristiansen C, Pedersen A, Christensen MS. Optimal diagnosis in acute myocardial infarction. A cost-effectiveness study. Circulation 1980; 61: 723-8.

21 Gibson RS, Boden WE, Theroux $P$, et al. Diltiazem and reinfarction in patients with non-q-wave myocardial infarction. N Engl J Med 1986; 315: 423-9.

22 Coll S, Castañer A, Sanz G, et al. Prevalence and prognosis after a first nontransmural myocardial infarction. Am J Cardiol 1983; 51: 1584-8.
23 Hutter AM Jr, DeSanctis RW, Flynn T, Yeatman LA. Nontransmural myocardial infarction: a comparison of hospital and late clinical course of patients with that of matched patients with transmural anterior and transmural inferior myocardial infarction. Am J Cardiol 1981; 48: 595-602.

24 Marmor $A$, Sobel $B E$, Roberts $R$. Factors presaging early recurrent myocardial infarction ("extension"). Am J Cardiol 1981; 48: 603-10.

25 Marmor A, Geltman EM, Schechtman K, Sobel BE, Roberts $R$. Recurrent myocardial infarction: clinical predictors and prognostic implications. Circulation 1982; 66: 415-21.

26 Cho HW, Meltzer HY, Joung JI, Goode D. Effect of incubation in human plasma on electrophoretic mobility of brain-type creatine phosphokinase. Clinica Chimica Acta 1976; 73: 257-65.

27 Mangano DT, Hollenberg $M$, Fegert $G$, et al. Perioperative myocardial ischemia in patients undergoing noncardiac surgery - I: Incidence and severity during the 4 day perioperative period. J Am Coll Cardiol 1991; 17: 843-50. 